\title{
A high-flow humidograph for testing the water uptake by ambient aerosol
}

\author{
Harry M. ten Brink ${ }^{\mathrm{a}, *}$, Andrey Khlystov ${ }^{\mathrm{a}}$, Gerard P.A. Kos ${ }^{\mathrm{a}}$, \\ Thomas Tuch ${ }^{\mathrm{b}}$, Christa Roth ${ }^{\mathrm{c}}$, Wolfgang Kreyling ${ }^{\mathrm{c}}$ \\ ${ }^{a}$ Netherlands Energy Research, Foundation (ECN) Westerduinweg 3, 1755 ZG Petten, Netherlands \\ ${ }^{\mathrm{b}}$ Ludwig-Maximilian-University, Institute of Medical Data Management, Biometrics and Epidemiology, Neuherberg/Munich, Germany \\ ${ }^{\mathrm{c}}$ GSF National Research Center for Environment and Health, Institute for Inhalation Biology, Neuherberg/Munich, Germany
}

Received 27 October 1999; received in revised form 22 February 2000; accepted 28 March 2000

\begin{abstract}
A "humidograph" with an air flow rate of $0.4 \mathrm{~m}^{3} \mathrm{~s}^{-1}$ was built to investigate the uptake of water and its effect on sizing, collection and light scattering of ambient aerosol. In the humidograph the relative humidity $(\mathrm{RH})$ can be scanned over a large RH trajectory. Its performance was assessed with laboratory particles of ammonium nitrate, ammonium sulfate and sodium chloride that are the major hygroscopic components of ambient aerosol. The increase in size at the deliquescence points, which ideally is a stepwise function of $\mathrm{RH}$, occurs over a range of $3 \% \mathrm{RH}$ units. This is shown to be an optimum value in a system of such large dimensions. Because the vapor pressure of ammonium nitrate increases significantly with temperature, its evaporative loss was investigated as a function of heating/drying temperature. The loss of pure test aerosol, with a mass distribution similar to that in the ambient atmosphere, was found to be acceptable for drying temperatures of up to $40^{\circ} \mathrm{C}$. The sizing of deliquesced aerosol by LAS-X monitors was tested and found to be a complex function of RH. In Berner low-pressure impactors growth of hygroscopic aerosol was not observed, not even at an RH approaching saturation. (C) 2000 Elsevier Science Ltd. All rights reserved.
\end{abstract}

Keywords: Aerosol; Sizing; Collection; Deliquescence; Ammonium nitrate

\section{Introduction}

\subsection{Water uptake by ambient aerosol}

Submicron aerosol in the Netherlands consists for a good part of hygroscopic salts like ammonium sulfate, ammonium nitrate and sodium chloride. Aerosol particles containing these components are present as saline droplets at a relative humidity $(\mathrm{RH})$ which exceeds the deliquescence point of the salts. Due to hysteresis, such aerosol particles lose water at an appreciably lower RH

\footnotetext{
* Corresponding author. Tel.: + 31-224-56-41-48; fax: + 31224-56-34-88.

E-mail address: tenbrink@ecn.nl (H.M. ten Brink).
}

than the deliquescence point, see Table 1 . This is the reason that aerosol can be present in the form of metastable droplets, even at low RH (e.g., Rood et al., 1989).

Aerosol can be "wet" or dry in an RH regime between deliquescence point and "efflorescence" point. The efflorescence point is the $\mathrm{RH}$ at which the accreted water is lost when the RH is being lowered; it is also known as crystallization or drying point. The phase of state of the aerosol, i.e. whether it is wet or dry has a great influence on parameters like size and light scattering, and on collection. To assess the phase of state of ambient aerosol and its influence on the mentioned aerosol characteristics a special system ("humidograph") was built. The term humidograph stands for a system in which the $\mathrm{RH}$ can be scanned over a large RH trajectory. In a humidograph the RH is being varied, either by humidification or/and subsequent drying or by changing the air 
Table 1

Deliquescence and efflorescence RH (in \%) for the dominant hygroscopic components of aerosol in the Netherlands ${ }^{\mathrm{a}}$

\begin{tabular}{|c|c|c|c|c|c|c|}
\hline & \multirow[t]{2}{*}{$\left(\mathrm{NH}_{4}\right)_{2} \mathrm{SO}_{4}$} & \multirow[t]{2}{*}{$\mathrm{NH}_{4} \mathrm{NO}_{3}$} & \multicolumn{3}{|c|}{$\left(\mathrm{NH}_{4}\right)_{2} \mathrm{SO}_{4} / \mathrm{NH}_{4} \mathrm{NO}_{3}$} & \multirow[t]{2}{*}{$\mathrm{NaCl}$} \\
\hline & & & $2: 1$ & $1: 1$ & $1: 2$ & \\
\hline Deliquescence RH & 81 & 62 & 61 & 56 & 58 & 75 \\
\hline Efflorescence RH & $40-42$ & $<8$ & $23-28$ & $18-22$ & $<8$ & $46-48$ \\
\hline
\end{tabular}

${ }^{a}$ Since ammonium sulfate and ammonium nitrate are mostly present as an internal mixture, deliquescence and efflorescence points for laboratory aerosol with a mass ratios which are commonly observed are also tabulated. The points were determined in the present humidograph (Dougle et al., 1998).. Drying of aerosol occurs over a range of RH and the efflorescence point tabulated here is the RH at which $50 \%$ of the aerosol is dry. The deliquescence $\mathrm{RH}$ of the mixtures is that of the first deliquescence point.

temperature, or by a combination of the two methods (Rood et al., 1985).

\subsection{Design criteria for the humidograph}

An RH scan should be performed over an RH range that is also encountered by the aerosol in the ambient atmosphere. The present system is predominantly used to assess the water uptake of ambient aerosol in a changing $\mathrm{RH}$ environment as encountered in atmospheric convections. In the updraft regions of such convections the RH rapidly increases because of adiabatic cooling, while air heats and dries in the downdraft regions. Whether the efflorescence point of the aerosol is passed is not known. On the other hand, most often clouds form in the upward region of the convections which is evidence that the deliquescence point of all hygroscopic aerosol components has been exceeded and that the aerosol is in a wet state before drying in the downdrafts. The fact that all aerosols goes through a very high $\mathrm{RH}$ regime is the reason to use a high $\mathrm{RH}$ as the reference starting situation in the present humidograph.

The high RH is induced with a very efficient humidifier at the entrance of the system. We thus followed the design of the humidograph of Rood et al. (1985), who used a humidifier to force the aerosol in a reference wet state. The minimum RH value to be obtained in the system should be similar to the lowest value encountered in $\mathrm{RH}$ in the Netherlands, which is close to $25 \%$.

The humidograph should enable testing of the effect of $\mathrm{RH}$ on the collection of aerosol. Such collection systems have rather high sampling flow rates and the humidograph has therefore large dimensions and an associated large air flow to allow undisturbed siting of several collectors in parallel at the exit. The large dimensions require special efforts to properly set and vary $\mathrm{RH}$ and a mere upscaling of existing low-flow humidographs was therefore not possible. As mentioned a major design criterion was the high reference $\mathrm{RH}$ at the entrance, see above, which requires precise setting of $\mathrm{RH}$ in order not to generate supersaturations and associated large droplets. Furthermore, very narrowly spaced heat exchangers were used to change the air temperature in the humidograph. This guaranteed that very small gradients in temperature and thus in $\mathrm{RH}$ exist across the air flow, as will be discussed in detail below.

\subsection{Aerosol size as a function of $R H$}

To measure the change in size of aerosol as a function of RH, an LAS-X optical particle sizer was used, following Tang (1980), who applied a predecessor of this instrument to study the deliquescence behavior of laboratory salts. As will be demonstrated below, we observed a substantial loss of water from deliquesced particles. Because of this problem, the change in size of the aerosol as a function of RH was checked with integrating nephelometers. In such instruments, the air is not dried and it will be shown in the present paper that they are excellent monitoring tools in a humidograph.

It has been argued that loss of water from wet aerosol can occur in LAS-X monitors due to mixing of the wet sampling air with drier sheath air (Biswas et al., 1987). Drying of the aerosol should be a function of the time available for mixing of sample air and sheath air. It was expected that an LAS-X monitor with a much larger flow rate than the standard instrument would not show significant drying and could therefore be used to properly measure the size of deliquesced aerosol. This hypothesis was tested here.

\subsection{Collection of wet aerosol}

The standard way of determining the mass distribution of aerosol is by collection in low-pressure jet cascade impactors. In impactors, the particles are separated according to their aerodynamic size. "Wet" particles with the same intrinsic mass of ammonium sulfate have a larger inertia because of the acrreted water than their dry counterparts and are therefore classified at larger sizes in a cascade impactor. The distribution of ammonium sulfate mass as a function of size should therefore be shifted by to larger diameters for the "wet" aerosol relative to that of the dry aerosol. There could be an additional 
artificial shift in the mass distribution of the wet aerosol because of extra hygroscopic growth of the wet aerosol, as discussed next.

In low-pressure jet impactors adiabatic cooling of the air occurs which could result in an increase in $\mathrm{RH}$ of up to $20 \%$ and an associated accretion of water by hygroscopic aerosol (Biswas et al., 1987). The accretion of water inside the impactor would therefore give a distortion of the wet mass distribution to larger sizes. For dry aerosol the above-mentioned increase in $\mathrm{RH}$ does not give rise to an increase in size. Wang and John (1988) showed that in Berner low-pressure impactors such a projected increase in size was not significant. However at the rather low RH used in that study $(69 \%)$, the aerodynamic size of the aerosol is not very sensitive to an increase in humidity. Because growth of hygroscopic aerosol sharply increases close to saturation $\mathrm{RH}$, the mentioned sampling artifact could be substantial at higher RH. We, therefore, repeated the tests at $\mathrm{RH}$ values up to saturation.

\subsection{Aerosol loss}

Undisturbed transmission of particles is a central requirement in an aerosol circuit. Since the focus of our research is assessment of the effect of $\mathrm{RH}$ on the mass distribution of the submicron aerosol, depositional losses should be very limited. A far more serious problem could be the loss of semi-volatile ammonium nitrate, which is a dominant aerosol component in the Netherlands (ten Brink et al., 1997). This aspect will be discussed in more detail below.

\subsection{Evaporation of ammonium nitrate}

In the atmosphere, ammonium nitrate is virtually in equilibrium with its associated gaseous compounds (ammonia and nitric acid). The reason for this is that exchange of the gases with the aerosol is rapid relative to a change over time in the concentration of aerosol and gases (e.g., Harrison and MacKenzie, 1988). Once the aerosol and associated gases enter the system, nitric acid and ammonia are removed in the humidifier, because it acts as an efficient gas scrubber.

After passing the humidifier the particulate ammonium nitrate starts to evaporate to reestablish the equilibrium with the gases. The ammonium nitrate aerosol as measured at the exit would then not be representative of the ammonium nitrate aerosol actually present outside. The evaporation of ammonium nitrate was considered to be so important that it was provisionally tested, immediately after commissioning of the humidograph (Dougle and ten Brink, 1997) and was found not to be high in the first preliminary tests.

Bergin et al. (1997) published a detailed study on the evaporation of ammonium nitrate in an integrating nephelometer. They specifically investigated the loss as a function of temperature because heating is used to dry the air. We extrapolated the results of Bergin et al., to a loss in our system, taking into account the larger dimensions, on the one hand, and the longer residence time on the other. This analysis showed that a significant loss was expected at drying temperatures used to decrease the RH to very low values. Therefore, special emphasis was given to assess the effect of heating/drying on the evaporative loss of ammonium nitrate in the system.

\section{Methods}

\subsection{Humidograph}

The flow scheme of the new high-flow humidograph is sketched in Fig. 1. Outdoor air (from a height of $5 \mathrm{~m}$ above the ground) is filtered and forced through the humidograph by means of a blower. The air flow is adjustable, but mostly its maximum flow of $0.4 \mathrm{~m}^{3} \mathrm{~min}^{-1}$ was used because then the spread in residence time is at a minimum.

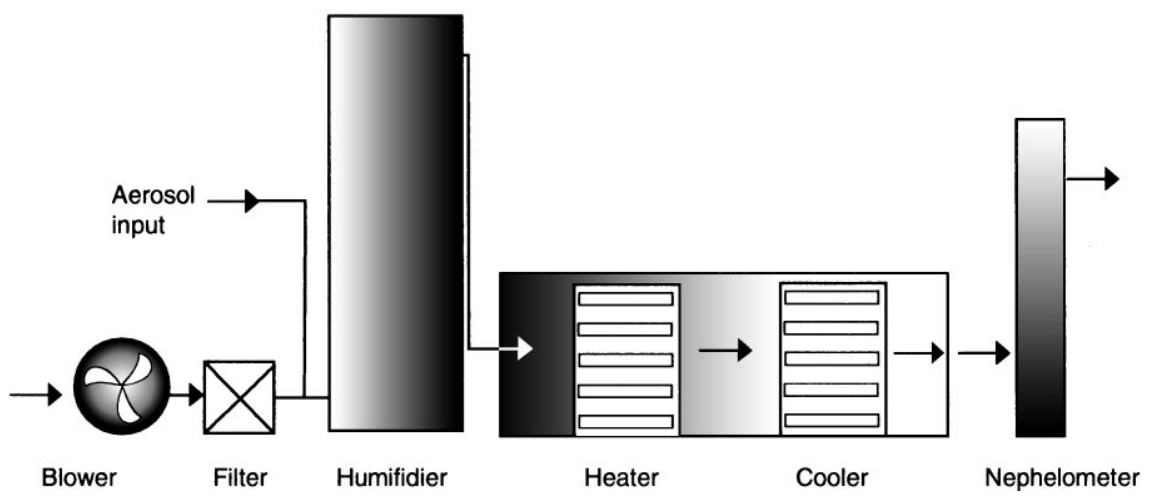

Fig. 1. Flow diagram of the humidograph. 
The air first passes the humidifier, for reasons discussed in the introduction, which consists of a tower of 1001 filled with loosely packed very open ceramic rings with a length of $30 \mathrm{~mm}$ and a diameter of $20 \mathrm{~mm}$. Demineralized water is gently sprinkled over these rings. The air is thus humidified in counterflow. The water is heated and its temperature thus determines the water vapor content of the air leaving the humidifier, see also Khlystov et al. (1996). The RH of the air leaving the humidifier is typically around $98 \%$, as determined with a calibrated dew-point meter with a precision of better than $0.5 \%$ RH units. At this RH all hygroscopic aerosol components of ambient aerosol, even sodium sulfate with a deliquescence point at $94.5 \% \mathrm{RH}$, are in a reference wet state.

In a heat-exchanger (Fig. 1) which follows the humidifier the air is heated and consequently the $\mathrm{RH}$ is lowered. The heat-exchanger consists of a series of parallel, narrowly spaced blades connected to a spiraling steel-tubing with water used as the heating liquid. The air volume of the heat-exchanger is 5 liters. After passing through this part the air is subsequently cooled and the RH increases in a similar heat-exchanger. This one has a somewhat larger dimension (10 liters volume) to allow an even more precise adjustment of the air humidity, as described further on. After a short mixing volume the various aerosol monitors sample from the air exiting the cooler. Under normal operation a realistic minimum RH in the humidograph is $25 \%$. The RH setting of the humidograph was calibrated using the sharp change in the size of hygroscopic salt aerosols at their deliquescence point as an internal standard.

In the standard approach the humidity of the air in the humidograph is varied by changing the temperature of the humidifier and thus the amount of water vapor in the air. The temperature of the final heat-exchanger is kept at room temperature so that no change in temperature and associated humidity occurs between this last heat-exchanger and the monitors/samplers.

For testing the characteristics of the humidograph reference aerosol is used and a high-efficiency filter, placed between blower and humidifier (Fig. 1), removes ambient aerosol. It was observed that with an air pump at the exit of the humidograph and in the absence of generated aerosol a significant concentration of aerosol was present at the exit of the humidograph. This was obviously caused by leakage of room air with aerosols into the humidograph behind the filter. Indeed, with a blower pressing the air through the humidograph the concentration was less than $0.1 \%$ of the room or outside aerosol number concentration.

\subsection{Scanning mode operation}

In scanning mode operation, the $\mathrm{RH}$ of the humidograph is gradually changed as a function of time. This is primarily achieved by variation of the temperature of the water in the humidifier. A requirement for measurement of ambient aerosol is that a scan should be limited to approximately $1 \mathrm{~h}$ to cover the complete hysteresis loop. During this period the aerosol generation should not significantly change in concentration or in size distribution. This corresponds to a scan rate of $2 \% \mathrm{RH}$ units per minute, which is then the typical rate used in the humidograph.

\subsection{Aerosol instrumentation}

Various aerosol instruments were applied to characterize and to sample the aerosol. Their inlets are located at the exit of the humidograph parallel to the sampling inlet of the integrating nephelometer, shown in Fig. 1, which serves as the central primary reference tool for reasons described before.

A CPC (TSI-3022) measured total aerosol number concentration. The light-scattering coefficient of the aerosol was assessed with integrating nephelometers (two MRI-1560 instruments). With an SMPS/DMPS (TSI 3070) the spectrum of the dried aerosol in the range of $10-250 \mathrm{~nm}$ was measured. These instruments were also used to assess the transmission of aerosol in the various parts of the humidograph.

The possible difference in response to wet and dry aerosol of two LAS-X optical particle counters was tested. These instruments measure the number of particles in size classes between 0.1 and $2.5 \mu \mathrm{m}$ diameter. The monitors were of the same internal design, but a different sampling flow rate and data evaluation: one sizer samples at a rate of $1 \mathrm{~cm}^{3} \mathrm{~s}^{-1}$ with spectra in 16 size channels, the second samples at $5 \mathrm{~cm}^{3} \mathrm{~s}^{-1}$, with a 45 channel size resolution. The size spectra were translated into volume distributions as a function of size class, assuming sphericity of the particles. This seems a proper assumption in the Netherlands for the regional aerosol, because it is virtually always present as wet entities (ten Brink et al., 1996). Such wet particles would approach a spherical shape of droplets.

Two identical 8-stage Berner low-pressure impactors, with a flow rate of $281 \mathrm{~min}^{-1}$ were used to sample the aerosol. In one, foils of aluminum are the standard substrates, while in the other polyethylene foils with an aluminum coating are applied. The recovery, analysis and detection limits of the ammonium sulfate have been described elsewhere (ten Brink et al., 1997); the amount of material sampled here was far above the detection limit.

\subsection{Generation and behavior of laboratory aerosol in the humidograph}

A prerequisite in performing tests with laboratory aerosols which should simulate ambient aerosol, is 
a proper concentration and size distribution. Sterk et al. (1984) showed that a Wiesbadener Doppel Inhalator jet-nebulizer provides the optimal aerosol in this respect. Another requirement, namely longer term stability of the output in terms of concentration and size distribution, was similar to that in the large ECN-cloud chamber (Khlystov et al., 1996). Extensive testing there showed that of all generators tested, again, a (modified) Wiesbadener Doppel Inhalator jet-nebulizer had the best stability over a period of several hours. To achieve this long-term performance a modification was made to the standard nebulizer by which the nebulizing solution is circulated between the nebulizer and a large reservoir using a peristaltic pump. This avoids concentrating of the salt solution in the generator due to the evaporation of the water. Stability tests in the present setup were performed, in which the generator was continuously operating for up to $4 \mathrm{~h}$.

The size of the (dried) aerosol was controlled by the concentration of the salt in solution and was chosen to be similar to that of ambient aerosol (in the Netherlands) of which the average mass median diameter is $0.5 \mu \mathrm{m}$ (ten Brink et al., 1997). The width of the (lognormally) distributed spectrum is close to 2 (Sterk et al., 1984) and this is also close to that in the atmosphere. Ammonium sulfate and sodium chloride, major constituents of ambient aerosols, were used as prime reference material.

The aerosols were injected into the air flow directly upstream of the humidifier. Time and spatial changes of the total aerosol number concentration, measured by a CPC (TSI 3022), were used to characterize the flow of the humidograph and the stability of test aerosol production. Occasionally, a DMPS/LAS combination was used to check the stability of the size (distribution) over the period during which aerosol measurements or collection were performed.

\subsection{Characterization of the change in aerosol size with varying $R H$}

The above-mentioned integrating nephelometers, which measured the collective light scattering of the aerosol, were used as the reference monitors for characterization of the change in aerosol size in the tests in which the RH was varied. Integrating nephelometers are very sensitive to a change in particle size in the size range of interest here, viz., $0.2-1.5 \mu \mathrm{m}$ (White, 1986). The response time of a nephelometer is of the order of seconds and its accuracy is $99 \%$ or better at the present aerosol concentrations.

The most important advantage of the instrument is that the aerosol in the measuring volume is not dried because of its large dimensions. The air in the measuring volume is not heated by the lamp, because of the short pulsing of the flash light, which was the reason not to use more recently acquired instruments (Belfort, 1590) which have appreciable internal heating. Another advantage of a nephelometer is that it is the only aerosol instrument for which the long-term stability can be checked in an absolute sense, viz., by using the light scattering of inert gases as a calibration source. In addition, there is an internal diffuser as an internal check on the light-system.

\subsection{Evaporation of ammonium nitrate}

The concentration of ammonium nitrate entering the humidograph was measured with an automated steam collector that provides continuous concentration values for ammonium and half-hourly values of the concentration of nitrate (Mikuska et al., 1997). The extent of evaporation of ammonium nitrate depends on the concentration of the dissociation products, nitric acid and ammonia present. It can be safely assumed that the highly adsorptive nitric acid is rapidly and permanently removed from the gas phase. However, ammonia is less adsorptive. For this reason, the concentration of ammonia gas was recorded. This was done with an on-line home-built ammonia detector ("AMANDA") (Wijers et al., 1993).

\section{Results and discussion}

\subsection{Performance of the humidograph}

\subsubsection{Humidity setting}

The RH setting of the humidograph is achieved with rather well-calibrated RH sensors (Vaisala). However, these are located in the centerline of the flow in the humidograph and thus not representative for the $\mathrm{RH}$ at off-axis sites. Furthermore, even the $\mathrm{RH}$ at the axis is an average of the RH of air passing close to the surface of the blades in the heat-exchanger and air that passes through the center of the narrow channels. It is not possible to measure or register all of those features, but there appears to be an internal reference for the setting of the humidograph. These are the deliquescence points of the various reference hygroscopic aerosols, together with the spread in the increase in aerosol size at the deliquescence $\mathrm{RH}$. It was found that the overall spread in $\mathrm{RH}$ at the exit is of the order of $2 \% \mathrm{RH}$ units (see also Section 3.5).

The humidograph is operated to a maximum $\mathrm{RH}$ of close to $90 \%$. The reason not to go higher is that beyond this $\mathrm{RH}$ value the uncertainty in the $\mathrm{RH}$ setting results in a very large uncertainty in the size of the particles, which is due to the exponential character of water uptake as a function of $\mathrm{RH}$. The minimum $\mathrm{RH}$ that can be achieved depends on the difference in the dew point of the outside air and the maximum heating temperature. It typically is around $25 \%$. 


\subsection{Transmission of ambient aerosol through the humidograph}

The transmission of ambient aerosols through the complete system as well as some critical parts like blower and humidifier was determined with CPC, DMPS and LAS-X; it was found that the loss for aerosols with diameters up to $3 \mu \mathrm{m}$ is less than $10 \%$. In our applications the upper diameter of the aerosols is $2.5 \mu \mathrm{m}$ and thus the loss of relevant aerosols is negligible. The rather low loss of aerosols of the given size in the humidifier is explained by its open structure.

\subsection{Flow characteristics of the humidograph}

It was found that for the test aerosols there is less than $2 \%$ random difference over a period of $15 \mathrm{~min}$ in the aerosol concentration at the center of the exit as compared to the concentrations at off-axis sites. This is even stronger evidence of a good mixing of aerosol stream and main air flow.

The flow characteristics of the humidograph were further tested by switching the aerosol generator on (or off) and following the change in concentration at the exit as a function of time. At the typical flow rate of $0.4 \mathrm{~m}^{3} \mathrm{~min}^{-1}$ the response of the particle concentration is as given in Fig. 2; it appears to be very reproducible. The first detectable change in particle concentration occurs $10 \mathrm{~s}$ after particle injection, and after $40 \mathrm{~s}$ the aerosol concentration is at $90 \%$ of the final value, see Fig. 2. The associated transit velocity is rapid compared to the rate at which the RH is varied, see above.

\subsection{Stability of the aerosol generation}

The stability in the output of the Wiesbadener Doppel Inhalator over a period of an hour can be judged from the light scattering of the nephelometer that is a good measure for the mass concentration. Fluctuations as shown in Fig. 3 were similar to those in the total number concentration. Over a period of $4 \mathrm{~h}$ a decrease in lightscattering signal and number concentration of $7 \%$ was observed. The relative magnitude of the short-term fluctuations did not change during operation; dry and wet aerosol behaved similarly.

\subsection{The scanning mode of the "humidograph"}

The performance of the humidograph in the scanning mode was checked using the increase in aerosol light scattering of pure laboratory salts at the respective deliquescence points due to abrupt water uptake as an internal reference. It is seen that this increase does not occur at a single deliquescence RH (Fig. 4), but over an RH range of close to $3 \% \mathrm{RH}$ units. This spread in humidity

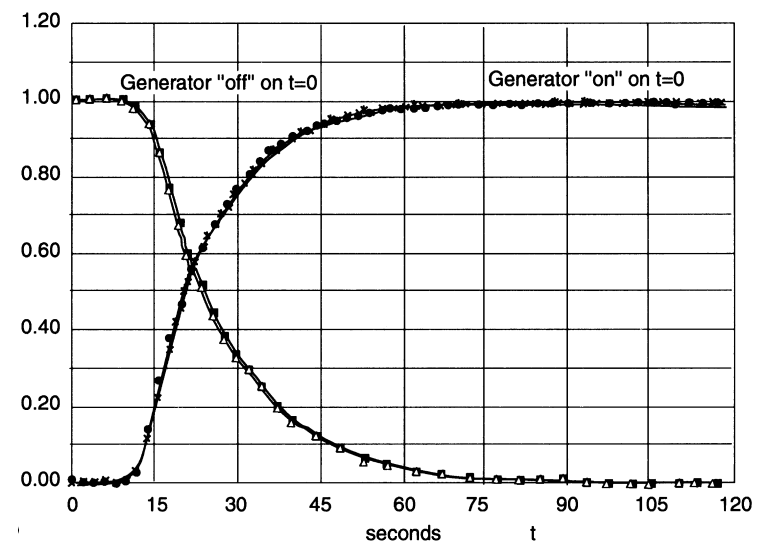

Fig. 2. Concentration of aerosol at the center of the exit plane of the humidograph as a function of time after starting, respectively stopping of the generation of particles at time $t=0$.

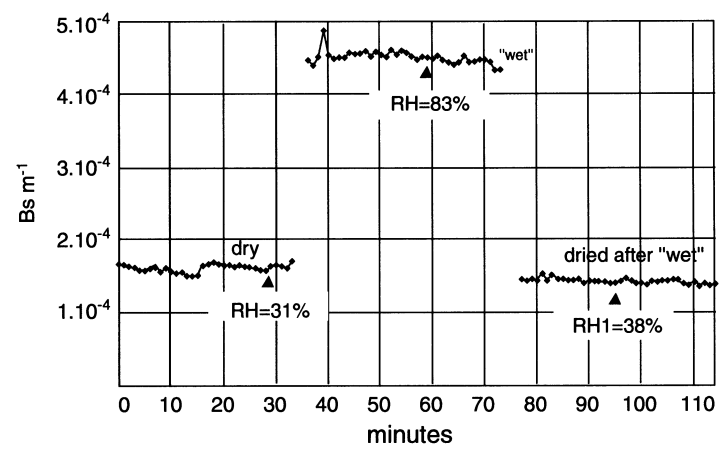

Fig. 3. Integrated light-scattering signal of ammonium sulfate test aerosol: (I) dry aerosol; (II) wet aerosol; (III) wet aerosol after drying.

over which the increase in light scattering and deliquescence occurs can be explained in part by the characteristics of the flow in the humidograph, as follows. The RH is increased at a rate of $1 \% 30 \mathrm{~s}^{-1}$. Together with some spread in residence time after the aerosol leaves the location of the heat-exchanger this should lead to a broadening of the response at the deliquescence point of slightly more than $1 \% \mathrm{RH}$ units.

In the more refined 'humidograph' of Rood et al. (1985), the deliquescence trajectory was approximately $1 \% \mathrm{RH}$. However, it should be considered that the present humidograph has a much higher flow rate. The extra broadening in our humidograph is explained by temperature gradients inside the cooler, as indicated also by Rood et al. in their humidograph. These gradients occur because in the narrow channels the air stream is laminar and as a consequence air passing along the cooling blades of the cooler is colder than air passing through the center of the air channels between the cooling blades. Behind the cooler the different laminar air streams mix 
and the average temperature can be such that the average humidity is below the deliquescence point. However, the humidity of the air that passed along the cooling blades exceeded the deliquescence humidity and the aerosol in this air stream has deliquesced. This aerosol is not dried when it mixes with the dryer central air and the total humidity drops below the deliquescence point because of hysteresis. Thus part of the aerosol is in a wet state after the mixing.

A few tests were performed at a much slower $\mathrm{RH}$ scanning rate to better identify the spread in deliquescence $\mathrm{RH}$, which is a direct measure of the uncertainty in the setting of the RH. This turned out to give a value for the spread and thus of the setting of close to $2 \% \mathrm{RH}$ units.

To achieve an $\mathrm{RH}$ of $25 \%$ and less, which corresponds to drying/heating temperatures, at which the evaporative loss of ammonium nitrate becomes excessive, extra drying was achieved with addition of dry particle-free air. However, this led to such a decrease in aerosol concentration that the difference in light-scattering signal of wet and dry particles at the point of efflorescence was too
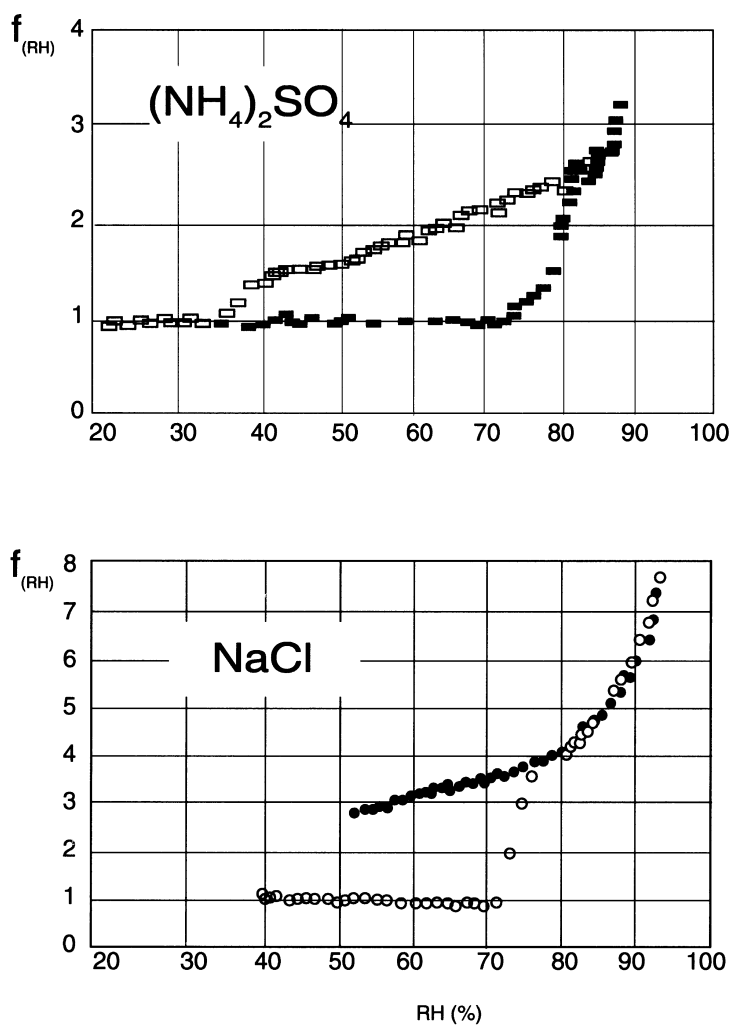

Fig. 4. Response of the integrating nephelometer to a change in RH. Upper panel: ammonium sulfate with a log-normal size distribution of a dry median mass diameter of $0.45 \mu \mathrm{m}$ and $\sigma_{\mathrm{g}}$ close to 2, see Fig. 6. Lower panel: sodium chloride with a similar log-normal size distribution as in the upper panel. small to be positively identified. A different approach was therefore followed to assess efflorescence at an RH less than $25 \%$. Use was made of the fact that aerosols which have been dried show a step-wise increase in size and light scattering when the $\mathrm{RH}$ is subsequently increased above the deliquescence point. In this second approach both heat-exchangers are used; the first serves as a heater/dryer and the second as a cooler of which the temperature is lowered so that $\mathrm{RH}$ increases as a function of time. The lowest $\mathrm{RH}$ in the entire humidograph, and thus that RH at which efflorescence occurs, is attained at the exit of the heater, and this $\mathrm{RH}$ is recorded. RHs as low as $8 \%$ were achieved.

\subsection{Evaporation of ammonium nitrate}

The results of duplicate tests on the temperature dependence of the evaporate loss of ammonium nitrate test aerosol and the associated decrease in light-scattering signal are given in Fig. 5. Up to a heating temperature of $40^{\circ} \mathrm{C}$ the decrease in signal is consistently small (less than $10 \%$ ), but large at temperatures exceeding $50^{\circ} \mathrm{C}$. For the aerosol size distribution used here the light scattering is approximately proportional to the square of the radius and therefore a decrease in surface of $10 \%$ corresponds to a decrease in aerosol mass of $15 \%$. This is considered as an acceptable loss also in view of the lower evaporative loss expected for ambient ammonium nitrate as will be shown next.

It has been demonstrated (Dougle et al., 1998) that ambient particulate ammonium nitrate in the Netherlands coexists with ammonium sulfate as an internal mixture. Evaporation of ammonium nitrate from internally mixed laboratory aerosols of the two compounds is significantly slower than that of pure ammonium nitrate (Khlystov et al., 1996); therefore, the evaporative loss of ammonium nitrate from ambient aerosol is certainly less than the values measured for the pure substance.

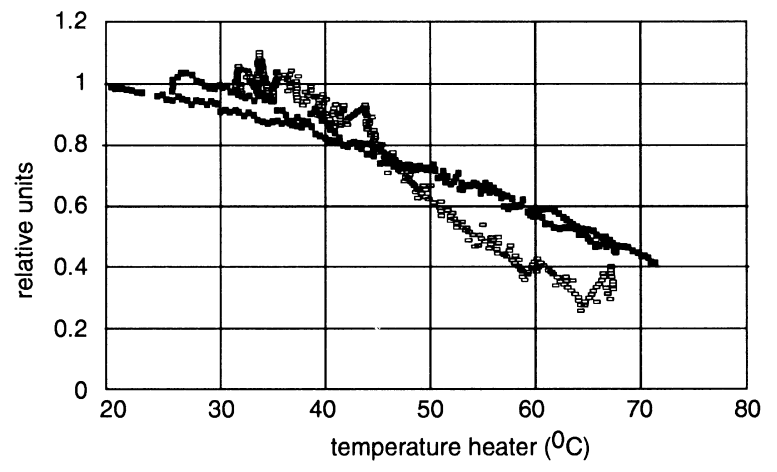

Fig. 5. Light scattering by ammonium nitrate aerosols with a mass distribution similar to that in Fig. 4, as a function of heating temperature in the heat exchanger closest to the exit. 
The maximum in the heating required to assess the humidity behavior of ambient aerosol depends on the lowest atmospheric RH to be simulated in the system. The lowest RH (25\%) reached in the Netherlands corresponds to a heating temperature of $40^{\circ} \mathrm{C}$. Thus maximum heating of the air can be confined to this temperature. As mentioned above, additional drying of the air in more fundamental tests was achieved by adding dry laboratory air.

\subsection{Sizing of deliquesced aerosol with LAS-X monitors}

The two LAS-X optical sizers, described earlier, measured the size spectra of ammonium sulfate aerosol used to simulate ambient aerosol. The spectra are presented in the upper panels of Fig. 6 as volume distributions for better comparison with the mass distribution obtained from the cascade impactors, described below. The dry spectrum at $35 \% \mathrm{RH}$ served as the reference distribution.

The spectrum of the wet aerosol, at $87 \% \mathrm{RH}$, was found to be identical to that of the dry aerosol for the two individual monitors (Fig. 6). (Note: The local minimum in the volume distribution at the wavelength of the light source $(0.6 \mu \mathrm{m})$ is a well-known artifact of the LAS. The difference between the spectra obtained with the two instruments is explained by the different data evaluation in the two devices, as described in Section 2.)

The great similarity in the spectra of the wet and dry aerosols is attributed to rapid drying of the deliquesced aerosol by mixing drier sheath air into the wet sample air. A possible explanation that the similarity is caused by a compensating effect, that is, that the (larger) droplets have a lower refractive index and thus scatter the same amount of light as their dry counterparts is ruled out by the following check.

An integrating nephelometer in which no drying occurs was used to measure the collective light scattering by the aerosol and the signal was compared to that when the air was periodically dried to $30 \% \mathrm{RH}$ before entering the same monitor. It was found that the light scattering by the wet aerosols was a factor of three higher than that by the dried aerosol (Fig. 3). The ratio of 3 in the lightscattering signal between wet and dry particles was close to the value of 2.8 calculated for this ratio for ammonium sulfate aerosols with an almost identical size/mass distribution (Boucher and Anderson, 1996).

The explanation why the sheath air is drier than the sample air is not simple, because the larger volume of the sheath air determines the $\mathrm{RH}$ and changes in fact the $\mathrm{RH}$ of the sampling air. There is some heating of the circulating sheath air, according to Biswas et al. (1987) which is caused by internal heating from the electronics of LAS-X. This should typically lead to a $10-15 \%$ decrease in $\mathrm{RH}$. This rather small change cannot explain the observed loss of water from the deliquesced aerosol. Biswas et al. (1987) discussed another phenomenon that could be the reason for drying. The filter cartridges are obviously
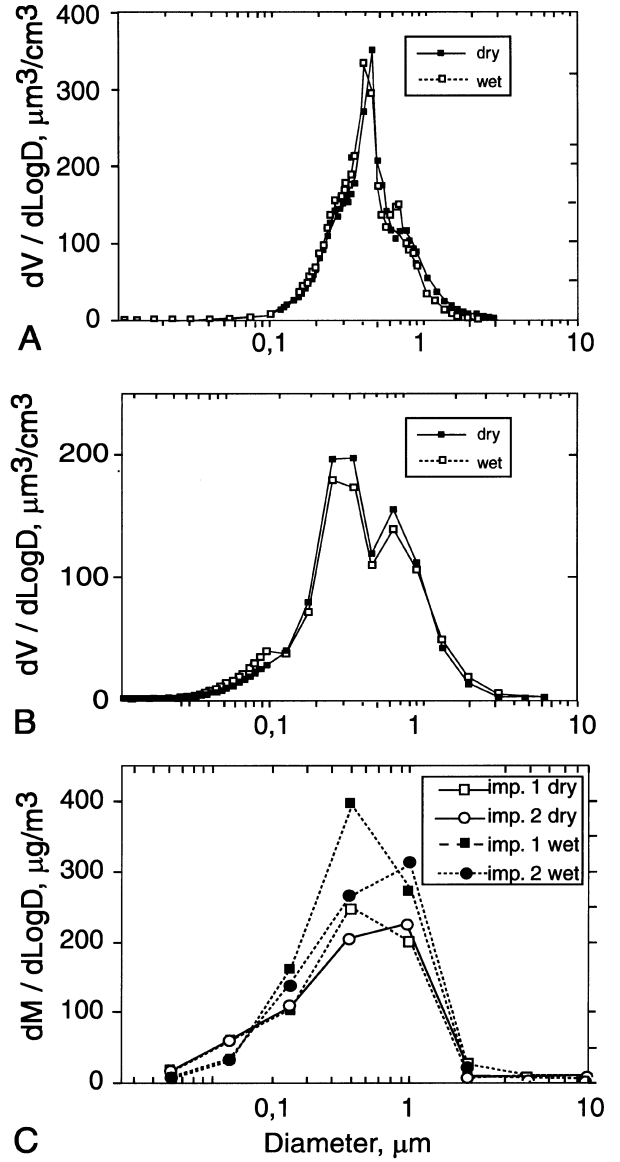

Fig. 6. Volume/mass distributions of ammonium sulfate under "dry" and "wet" conditions (35 and 87\% RH, respectively): (A) volume distribution as derived from the high-flow LAS-X optical sizer; (B) volume distribution as derived from the low-flow LAS$\mathrm{X}$ optical sizer; (C) mass distributions obtained with two Berner low-pressure impactors.

hygroscopic and collect and retain water vapor for an extended period of time (several hours according to Biswas et al., 1987). In case of "wet" experiments following dry tests, the filters are dry and have a large capacity for removing water vapor.

Drying of deliquesced aerosol, similar to that found in the laboratory, is expected to occur in ambient air in case of a change from low to high $\mathrm{RH}$. Vice versa, moisture collected in the filters during a wet period should be released and increase the $\mathrm{RH}$ of the sampling air in a subsequent dry period. To avoid such ambiguities the standard hygroscopic cartridges could be replaced by small hydrophobic filters (Biswas et al., 1987). However, this option has not been pursued here for the following reason. Our LAS monitors are being used in monitoring programs for detailed characteristics of ambient fine aerosol. The volume distribution derived from the size 
spectra serves as a proxy for the distribution of the fine aerosol mass. This mass pertains to the dry material and therefore the aerosol is also deliberately dried in the LAS monitors. This is accomplished by heating the inlet line.

\subsection{Addendum: aerosol growth in low-pressure impaction}

The same aerosol as used in the above tests was sampled with Berner low-pressure impactors and a search was made for possible growth of the "wet" aerosol due to adiabatic cooling inside the impactor, as discussed in the introduction. Without additional growth, the wet distribution should be shifted to larger diameters relative to that of the dry aerosol by some $40 \%$ (Biswas et al., 1987). In the actual measurements (Fig. 6c), wet and dry aerosol mass distributions were certainly not shifted by more than this value, from which it is concluded that growth by adiabatic cooling in the impactor does not occur.

More convincing evidence of an absence of such growth was obtained in experiments in which aerosol was sampled at an RH which was very close to saturation (in the ECN-cloud chamber; Kruisz, 1997). Under these conditions a small increase in $\mathrm{RH}$ leads to supersaturation and unlimited growth. In this case, the mass spectrum of the ammonium sulfate was compared with that derived from accurate in situ measurement of the droplet size and a shift in the mass distribution obtained with the impactor was not observed. This measured absence of growth supports the hypothesis that the reduced pressure in the Berner impactor compensates for the increase in RH due to adiabatic cooling (e.g., Howell et al., 1999).

\section{Concluding remarks}

A high-flow humidograph was built to test the hysteresis of water uptake of submicron aerosol. Performance tests with laboratory generated simulated ambient aerosol showed:

- The RH setting is stable over time periods of hours. The spread in RH is 3\% RH units for the highest flows which is sufficient for tests of instrumentation up to $90 \% \mathrm{RH}$. The spread is caused by a finite gradient in temperature in the air across the channels of the cooler perpendicular to the air stream.

- The evaporative loss of ammonium nitrate is less than $15 \%$ for heating/drying temperatures up to $40^{\circ} \mathrm{C}$.

- The humidograph is of a size that allows parallel testing of several aerosol samplers. The system was used to investigate possible artifacts in the collection of hygroscopic aerosols.

In LAS-X optical sizers rapid loss of accreted water of hygroscopic submicron aerosols was observed. The loss is apparently a very complex function of the internal drying of the monitors and it seems therefore highly preferable to dry the sampled aerosol to a low-reference $\mathrm{RH}$ when these monitors are to be used in long-term monitoring studies of ambient aerosol.

Water accretion of hygroscopic submicron aerosols does not occur in Berner low-pressure impactors.

\section{Acknowledgements}

This study was partly performed in the National Research Program on Climate Change (NOP-2) under contract no. 951205 with support by a grant from the Ministry of Economic Affairs of the Netherlands under Mefis no. 53478. The study with the LAS-X monitors and the impactors was performed within the framework of the EU-project - Exposure and risk assessment for fine and ultrafine particles in ambient air (ULTRA) -, which is funded by the EU ENVIRONMENT and CLIMATE Research Programme under Contracts ENV4-CT950205 and ENV4-CT97-0568 and co-ordinated by the Unit of Environmental Epidemiology, National Public Health Institute, Kuopio, Finland.

Pauline Dougle (ECN) and Arja Even (ECN) are gratefully acknowledged for their enthusiastic assistance in the experiments.

Preliminary data were presented at the European Aerosol Conference 1997 and the 5th International Aerosol Conference 1998. Of these presentations two-page abstracts appeared in the Summary Volume of Journal of Aerosol Science (S) of the respective years, see reference list.

\section{References}

Bergin, M.H., Ogren, J.A., Schwartz, S.E., McInnnes, L.M., 1997. Evaporation of ammonium nitrate in a heated nephelometer; implications for field measurements. Environmental Science and Technology 31, 2878-2883.

Biswas, P., Jones, C.L., Flagan, R.C., 1987. Distortion of size distributions by condensation and evaporation in aerosol instruments. Aerosol Science and Technology 7, 231-246.

Boucher, O., Anderson, T.L., 1996. GCM assessment of the sensitivity of direct climate forcing by anthropogenic sulfate aerosols to aerosol size and chemistry. Journal of Geophysical Research 100, 26117-26134.

Dougle, P.G., ten Brink, H.M., 1997. Evaporative losses of ammonium nitrate in nephelometry and impactor measurements. Journal of Aerosol Science 27, S511-S512.

Dougle, P.G., Veefkind, J.P., ten Brink, HM., 1998. Crystallisation of mixtures of ammonium nitrate, ammonium sulfate and soot. Journal of Aerosol Science 29, 375-386.

Harrison, R.M., MacKenzie, A.R., 1988. A numerical simulation of the kinetic constraints upon achievement of the ammonium nitrate dissociation equilibrium in the troposphere. Atmospheric Environment 24A, 91-102. 
Howell, S., Pszenny, A.A.P., Quinn, P., Huebert, B., 1999. A field comparison of three cascade impactors. Aerosol Science and Technology 29, 475-492.

Khlystov, A., Kos, G.P.A., ten Brink, H.M., 1996. A high-flow turbulent cloud chamber. Aerosol Science and Technology 24, 59-68.

Kruisz, C., 1997. Sampling of hygroscopic aerosols with cascade impactors. Thesis, University of Vienna; detailed result report available from the first author of the present publication.

Mikuska, P., Khlystov, A., ten Brink, H.M., Slanina, J., 1997. A system for on-line chemical analysis of aerosol species. Journal of Aerosol Science 28, S445-S446.

Rood, M.J., Larson, T.V., Covert, D.S., Ahlquist, N.C., 1985. Measurement of laboratory and ambient aerosols with temperature and humidity controlled nephelometry. Atmospheric Environment 19, 1181-1190.

Rood, M.J., Shaw, M.A., Larson, T.V., Covert, D.S., 1989. Ubiquitous nature of ambient metastable aerosol. Nature 337, 537-539.

Sterk, P.J., Plomp, A., van de Vate, J.F., 1984. Physical properties of aerosols produced by several jet- and ultrasonic nebulizers. Bulletin of European Physiopathology and Respiration 20, 65-72.

Tang, I.N., 1980. Deliquescence properties and particle size change of hygroscopic aerosols. In: Willeke (Ed.), Generation of Aerosols. Ann Arbor Science, Ann Arbor, MI, USA, pp. $153-170$.

ten Brink, H.M., Veefkind, J.P., Waijers-Ijpelaan, A., van der Hage, J.C., 1996. Aerosol light-scattering in The Netherlands. Atmospheric Environment 30, 4251-4261.

ten Brink, H.M., Kruisz, C., Kos, G.P.A., Berner, A., 1997. Size/composition of the light-scattering aerosol in the Netherlands. Atmospheric Environment 31, 3955-3962.

Wang, C.-H., John, W., 1988. Characteristics of the Berner Impactor for sampling inorganic ions. Aerosol Science and Technology 8, 157-172.

White, W.H., 1986. On the theoretical and empirical basis for apportioning extinction by aerosols: a critical review. Atmospheric Environment 20, 1659-1672.

Wijers, G.P., Otjes, R.P., Slanina, J., 1993. A continuous-flow denuder for the measurement of ambient concentrations of ammonia. Atmospheric Environment 27A, 2085-2090. 